\title{
Study of Deformation Mechanism on the Pipeline in Steep Longer Distance Seams Mining
}

\author{
Guoming Cheng ${ }^{1, a}$ Tongzu Liu' ${ }^{2, b}$ Yunlong Wang ${ }^{1, c}$ \\ ${ }^{1}$ China Institute of Geo-environment Monitoring, Beijing 100081, China; \\ ${ }^{2}$ Guangzhou Chemical Grouting Company, CAS, Guangzhou 510650, China \\ aguomingcheng@sohu.com, b liutz2011@163.com, ㄷwangyl@mail.cigem.gov.com
}

Key words : mining subsidence; buried pipeline ;numerical modeling; longer distance seams

\begin{abstract}
In order to understand the deformation mechanism on the pipeline in steep longer distance seams mining, taking one coal mine as case study, where the gas pipeline from Shanshan to Urumqi, in China is laid across. FLAC $^{3 \mathrm{D}}$ was adopted to study the deformation mechanism on the pipeline. The simulations reveal that little deformation occurred on the pipeline above the untapped thinner seam after the thicker seam mining, whereas vertical displacement increase about $27.5 \%$ on the pipeline above the mined thicker seam after the thinner seam mining, and the maximum deformation on the pipeline is at the location of about the centre of gob in the thicker seam, but no obvious deformation on the pipeline appeared above the rocks between the mined two seams; The possible damage to the pipeline occurs at the peak compressive stresses, which are at the gob centre, then at the two peak tensile stresses, which are at the outer edge of gob in the thicker seam. Therefore, the results are helpful to prevent and reduce the impact of subsidence on the pipeline.
\end{abstract}

\section{Introduction}

With the rapid development of China's pipelines for gas and oil, more pipelines have to be laid in subsidence areas of coal mines, hence the pipelines are faced with the impact and damage caused by mining subsidence [1]. For instance, the gas pipeline from shanshan to Urumqi, which is laid in one coal mine subsidence area, had been seriously affected since August, 2005[2].

Researches on the deformation mechanism of buried pipeline caused by mining have been conducted [3-12]. Peng S S et al. [3] based on the hypothesis that the buried pipeline subsides with the ground simultaneously, determined the magnitude and location of the maximum stresses on the pipeline by the PFIM (probability function integration method). Based on PFIM, Hong Wang et al. [6] predicted the largest subsidence volume and the allowed largest subsidence to assess whether or not the pipeline is safe. Xiaolin Wang et al. [8] used PFIM to predict deformation of the subsidence area and deduce the deformation compatibility equation of pipeline elongation, thus working out the stress and strain on the pipeline axis by iteration computation. Guoming Cheng et al. [9-12] studied the impact of mining subsidence on the pipeline safety using numerical analysis method. Significant achievements on pipeline deformation mechanism due to coal mining have been obtained. However, the research on subsidence-induced deformation and stress on the pipeline in longer distance seams mining is relatively scarce. Whether the deformation and stress on the pipeline within one seam is affected by another seam mining or not, and where the possible damage to the pipeline is, which are still unknown so far. The above problems need to be answered in order to prevent and reduce possible damage to the pipeline.

Taking one mine, where the gas pipeline from Shanshan to Urumqi is laid across, as case study, a finite difference numerical code, FLAC ${ }^{3 \mathrm{D}}$ was adopted to simulate the deformation and stress variation on the pipeline in longer distance seams mining, which provides theoretical basis for the safe operation of buried pipeline across subsidence areas in steep longer distance seams mining. 


\section{Description of background project}

The study site is some mine where the gas pipeline from Shanshan to Urumqi is laid across. There are two coal seams including No.45 and No.43 seam at the mine and their thickness are 40 and $60 \mathrm{~m}$ respectively with the spacing about $80 \mathrm{~m}$ between the two seams, and their seams dip angle is about 82 degree. The cover soil contains sand and gravel. The pipeline was laid underneath the covering soil of about $1.8 \mathrm{~m}$, and was perpendicular to the strike direction of the two seams. The pipe is made of steel, its diameter is $457 \mathrm{~mm}$, and its wall thickness is $6 \mathrm{~mm}$ with its permissible strength stress of $318 \mathrm{MPa}$.

\section{Numerical simulations}

\section{Numerical Model}

The numerical model, which is $340 \mathrm{~m}$ in $\mathrm{X}$ direction, $200 \mathrm{~m}$ in $\mathrm{Y}$ direction and $250 \mathrm{~m}$ in $\mathrm{Z}$ direction, in which the pipeline is $0-340 \mathrm{~m}$ in $\mathrm{X}$ direction, $0 \mathrm{~m}$ in $\mathrm{Y}$ direction and $1.8 \mathrm{~m}$ in $\mathrm{Z}$ direction. In order to analyze the deformation and stress evolution on the pipeline, shell element was adopted to model the pipe in FLAC ${ }^{3 \mathrm{D}}$. The model includes 98160 zones and 110474 nodes, in which including 4352 pipe zones and 2192 pipe nodes. Fig. 1 presents geometry of model showing the material layers.

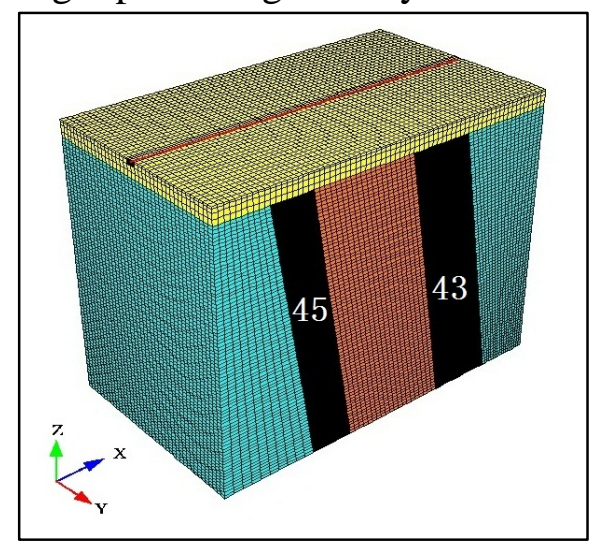

Fig.1 The three-dimensional model

\section{Material Parameters}

In order to simplify calculation in this research, Mohr-Coulomb constitutive model was adopted for geotechnical materials, and elastic model was adopted for the pipe. Parameter characteristics of different materials are shown in Tab.1.

Tab.1 M aterial Parameter Table

\begin{tabular}{|c|c|c|c|c|c|c|}
\hline Name of materials & $\begin{array}{l}\text { Density } \\
\left(\mathrm{kg} / \mathrm{m}^{3}\right)\end{array}$ & $\begin{array}{l}\text { Bulk modulus } \\
\quad(\mathrm{GPa})\end{array}$ & $\begin{array}{l}\text { Shear modulus } \\
\text { (GPa) }\end{array}$ & $\begin{array}{l}\text { Internal } \\
\text { friction } \\
\text { angle }\left({ }^{\circ}\right)\end{array}$ & $\begin{array}{c}\text { Cohesiv } \\
\text { e force } \\
(\mathrm{KPa})\end{array}$ & $\begin{array}{c}\text { Tensile } \\
\text { strength } \\
\text { (MPa) }\end{array}$ \\
\hline Cover soil & 1850 & 0.5 & 0.3 & 22 & 0.002 & 0.0005 \\
\hline $\begin{array}{l}\text { Rock between } \\
\text { seams }\end{array}$ & 2500 & 15.6 & 10.8 & 42 & 4.40 & 2.3 \\
\hline No.45 seam & 1300 & 2.3 & 1.1 & 35 & 1. 80 & 1.0 \\
\hline No.43 seam & 1300 & 2.1 & 1.0 & 35 & 1. 80 & 1.0 \\
\hline $\begin{array}{c}\text { Roof of No.43 } \\
\text { seam and floor of } \\
\text { No.45 }\end{array}$ & 2450 & 12.2 & 9.3 & 40 & 4.10 & 2.1 \\
\hline
\end{tabular}




\section{Analysis of working conditions}

In the model excavation steps was divided into three stages according to the actual mining levels. In the early stage the $1^{\text {st }}$ to $3^{\text {rd }}$ level in No.43 seam was mined, and in the middle stage the $3^{\text {rd }}$ level in No.43 seam was mined, and in the late stage the $1^{\text {st }}$ to $3^{\text {rd }}$ level was mined in No. 45 seam. Tab. 2 shows excavation depth at different mining levels in the two seams. In the simulations, Lateral boundary was restrained horizontally, bottom boundary was restrained vertically in the model, and top boundary was free.

Tab. 2 Excavation depth at different mining levels in No.43 and No.45 seams

\begin{tabular}{|c|c|c|c|c|c|c|c|c|}
\hline \multirow[b]{2}{*}{$\begin{array}{c}\text { Mining } \\
\text { level }\end{array}$} & \multicolumn{2}{|c|}{$1^{\text {st }}$} & \multicolumn{2}{|c|}{$2^{\text {nd }}$} & \multicolumn{2}{|c|}{$3^{\text {rd }}$} & \multicolumn{2}{|c|}{ Fourth } \\
\hline & Top(m) & $\begin{array}{c}\text { bottom } \\
(\mathrm{m})\end{array}$ & Top(m) & $\begin{array}{c}\text { Bottom } \\
\text { (m) }\end{array}$ & Top(m) & $\begin{array}{c}\text { Bottom } \\
\text { (m) }\end{array}$ & Top(m) & $\begin{array}{l}\text { Bottom } \\
\text { (m) }\end{array}$ \\
\hline $\begin{array}{c}\text { No.43 } \\
\text { seam }\end{array}$ & 17 & 32 & 42 & 52 & 67 & 87 & 107 & 147 \\
\hline $\begin{array}{c}\text { No.45 } \\
\text { seam }\end{array}$ & 16 & 31 & 41 & 51 & 66 & 86 & & \\
\hline
\end{tabular}

\section{Analysis of vertical displacements}

As shown in Fig.2, in the early stage, i.e., after mining the $1^{\text {st }}$ to $3^{\text {rd }}$ level of No.43 seam, the maximum displacement on the pipeline above No.43 seam is $1.204 \mathrm{~m}$, which is at the location of $220 \mathrm{~m}$ along the $\mathrm{X}$ axis direction, whereas no deformation occurred on the pipeline above No.45 seam. In the middle stage, i.e., after mining the fourth level of No.43, the maximum displacement on the pipeline above No.43 seam is $1.223 \mathrm{~m}$, which is at the location of $215 \mathrm{~m}$ along the $\mathrm{X}$ axis direction, whereas still no vertical displacement occurred on the pipeline above No. 45 seam. In the late stage, i.e., after mining the $1^{\text {st }}$ to $3^{\text {rd }}$ level of No.45 seam, the maximum displacement on the pipeline above No.45 seam is $0.29 \mathrm{~m}$, which is at the location of $70 \mathrm{~m}$ along the $\mathrm{X}$ axis direction, and the maximum displacement on the pipeline above No.43 seam is $1.559 \mathrm{~m}$, about $27.5 \%$ increase compared with the middle stage excavation, which is at the location of $220 \mathrm{~m}$ along the $\mathrm{X}$ axis direction. In addition, no obvious vertical displacement on the pipeline occurred above the rocks between the two seams.

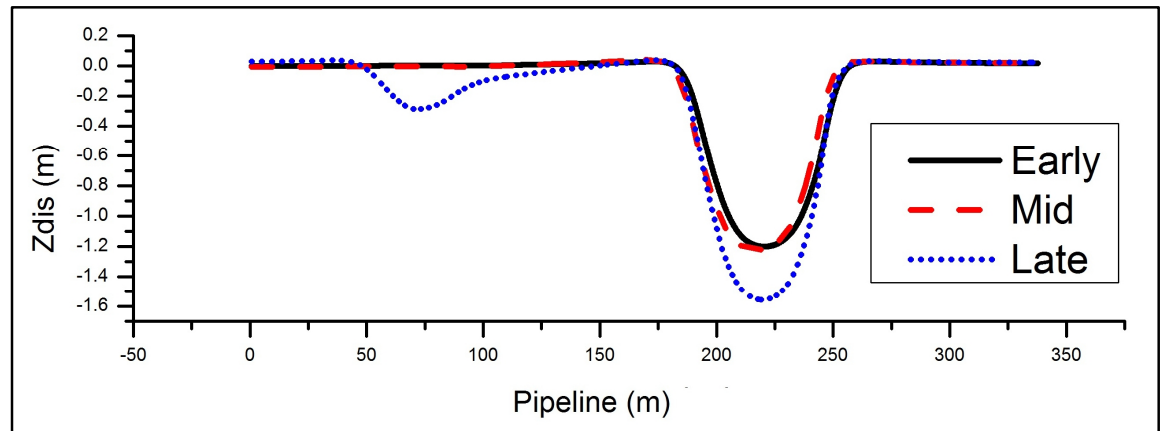

Fig. 2 vertical displacement on the pipeline at different mining stages

From the above discussion, it can be concluded that little deformation occurred on the pipeline above the untapped thinner seam after the thicker seam mining, whereas vertical displacement on the pipeline above the mined thicker seam increase about $27.5 \%$ after the thinner seam mining, and the maximum deformation on the pipeline is at the location of about the gob centre of the thicker seam. However, no obvious deformation on the pipeline appeared above the rocks between the mined two seams. 


\section{Analysis of axial stress}

From the above vertical displacement discussion it can be seen that larger deformation on the pipeline appeared in the zone above the mined thicker seam, therefore, the axial stress distribution on the pipeline was concentrated on the zone above the above the mined thicker seam. From Fig. 3 it can been seen that tensile stresses on the pipeline occurred at the two zone from $180 \mathrm{~m}$ to $204 \mathrm{~m}$ and from $240 \mathrm{~m}$ to $260 \mathrm{~m}$ along the $\mathrm{X}$ axial direction, which are at both the outer edge and the inner edge of the gob, in which the maximum tensile stress is $270 \mathrm{MPa}$, about $6 \mathrm{~m}$ outside the gob, and compressive stress on the pipeline occurred at the zone from $204 \mathrm{~m}$ to $240 \mathrm{~m}$ along the $\mathrm{X}$ axial direction, which are inside the gob, in which the maximum compressive stress is $280 \mathrm{MPa}$, at about the gob centre. So, the possible damage to the pipeline occurs at the peak compressive stresses, which are at the gob centre, then at the two peak tensile stresses, which are at the outer edge of gob in the thicker seam.

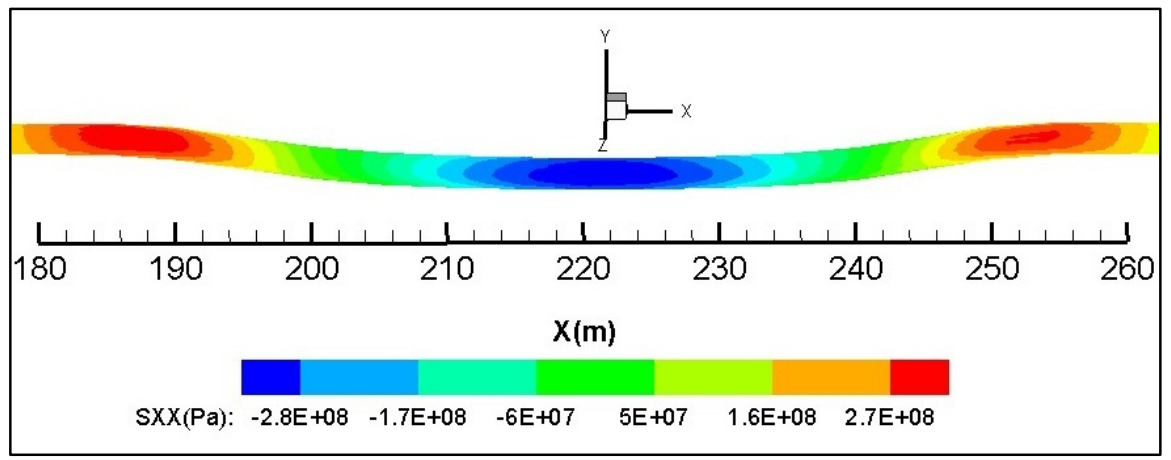

Fig.3 Axial stress distribution on the pipeline above gob in No.43 seam after final mining (gob range in No.43 seam along $X$ axial direction is from $190 \mathrm{~m}$ to $250 \mathrm{~m}$ )

\section{Conclusion}

When the spacing between two steep seams is about $80 \mathrm{~m}$ longer, little deformation occurred on the pipeline above the untapped thinner seam after the mining thicker seam, whereas vertical displacement on the pipeline above the mined thicker seam increase about $27.5 \%$ after mining the thinner seam, and the maximum deformation on the pipeline is at the location of about the centre of gob in the thicker seam, but no obvious deformation on the pipeline appeared above the rocks between the mined two seams; The possible damage to the pipeline occurs at the peak compressive stresses, which are at the gob centre in thicker seam, then at the two peak tensile stresses, which are at the outer edge of gob in the thicker seam. Therefore, the results are helpful to prevent and reduce the impact of subsidence on the pipeline in similar mining conditions.

\section{Acknowledgements}

This work was supported by the National Science Foundation of China (No.41172266) and the One Hundred Excellent Young Talents for Ministry of Land and Resources of China (No.2007). Thanks are due to China Petroleum Pipeline Engineering Corporation for providing the details of the mine and the pipeline. 


\section{References}

[1] J. Shuai, X.L. Wang, S.Z. Zuo. Welded Pipe and Tube (In Chinese).Vol.31 (5) (2008), p.9

[2] L. Li, G.M. Cheng, Z.P. Zhang. Y. Wang. Coal Mining Technology (In Chinese). Vol.18 (2) (2013), p. 67

[3] S.S. Peng, Luoy. Mining Science and Technology, Vol.6 (2) (1988), p.205

[4]Dearman W.R., Strachan Anne, Roche D.P., and Vincet. Bulletin of the International Association of Engineering Geology, Vol.25 (1982), p.19

[5] Hucka V J, Blair C K, Kimball E P. Mining Engineering, Vol.38 (10) (1986), p. 980

[6] H. Wang, M. Zhang, H.M. Chang. Petroleum Engineering Construction (In Chinese), Vol. $2(2008)$, p.26

[7] J.T. Wan, S.T. Hu. Land and Resources in Shandong Province (In Chinese). Vol. 6(2008), p.37

[8] X.L. Wang, J. Shuai, J.Q. Zhang. Rock and Soil Mechanics (In Chinese). Vol.32 (11) (2011), p.3378

[9] G.M. Cheng, W.P. Li, Z.F. Guo. Coal Mining Technology (In Chinese). Vol.15 (4) (2010), p.31

[10] G.M. Cheng, Z.P. Zhang. Coal Mining Technology (In Chinese). Vol.16 (5) (2011), p.35

[11] G.M. Cheng, T.Z. Liu, B. Zhi. Advanced Materials Research. Vol.448-453(2014), p.3863

[12] G.M. Cheng, W.J., Xu, H.B., Chu. Advanced Materials Research.Vol.838-841(2014), p.2202 